\title{
Multiple Spontaneous Simultaneous Intracerebral Hemorrhages
}

\author{
Jin-Suk Seo, Taek-Kyun Nam, Jeong-Taik Kwon, Yong-Sook Park \\ Department of Neurosurgery, Chung-Ang University College of Medicine, Seoul, Korea
}

\begin{abstract}
Simultaneous occurrence of intracerebral hemorrhage $(\mathrm{ICH})$ in different arterial territories is an uncommon event. We report on two cases of multiple spontaneous simultaneous $\mathrm{ICH}$ for which we could find no specific cause. A 73-year-old man, with no related medical history, was admitted to the hospital with simultaneous bithalamic $\mathrm{ICH}$, and subsequently died of recurrent pneumonia. Second patient was a 60-year-old man who presented with simultaneous $\mathrm{ICH}$ in the pons and thalamus; he died of recurrent bleeding. We review the possible pathological mechanisms, clinical and radiologic features of simultaneous multiple $\mathrm{ICH}$.
\end{abstract}

Keywords Simultaneous, Intracerebral hemorrhage, Hypertension, Multiple
$\mathrm{J}$ Cerebrovasc Endovasc Neurosurg.

2014 June; 16(2):104-111

Received : 10 February 2014

Revised : 25 March 2014

Accepted : 20 May 2014

\author{
Correspondence to Yong-Sook Park \\ Department of Neurosurgery, Chung-Ang \\ University College of Medicine, 102, Heukseok-ro, \\ Dongjak-gu, Seoul 156-755, Korea \\ Tel : 82-2-6299-1610 \\ Fax : 82-2-821-8409 \\ E-mail : cuttage@cau.ac.kr \\ ORCID : http://orcid.org/0000-0002-5931-4122 \\ This is an Open Access article distributed under the \\ terms of the Creative Commons Attribution Non- \\ Commercial License (http://creativecommons.org/li- \\ censes/by-nc/3.0) which permits unrestricted non- \\ commercial use, distribution and reproduction in any \\ medium, provided the original work is properly cited.
}

\section{INTRODUCTION}

The reported incidence of spontaneous intracerebral hemorrhage $(\mathrm{ICH})$ is 24.6 per 100,000 person-years, however, simultaneous multiple ICH are much more uncommon. $^{20)}$ The primary causes of single $\mathrm{ICH}$ are hypertension, tumor, vasculopathy, and coagulopathy, however, the causes of simultaneous multiple $\mathrm{ICH}$ are not known. We describe two cases of simultaneous multiple $\mathrm{ICH}$ for which we could not assign a direct cause and provide a review of the literature.

\section{CASE REPORTS}

\section{Case 1}

A 73-year-old man with no previous history of hypertension, diabetes mellitus, or other medical illnesses was admitted to our hospital emergency room due to a sudden onset of decreased mental status. He had never smoked and had an unremarkable history of cerebrovascular accidents. Upon arrival, the patient's mental status was drowsy; his total score on the Glasgow coma scale was nine (eye opening 2, verbal response 3, motor response 4 ). Isocoric pupil with $2 \mathrm{~mm} / 2 \mathrm{~mm}$ prompt light reflex and quadriparesis were noted. His right side motor grade was III, and his left side motor grade was IV.

Computed tomography (CT) showed hemorrhages in the bilateral thalami and an intraventricular hemorrhage in the bilateral lateral ventricles (Fig. 1). According to the laboratory results, complete blood count $(\mathrm{CBC})$, coagulation battery, and C-reactive protein (CRP) were all within normal range; however, the patient's erythrocyte sedimentation rate (ESR) was slightly elevated.

The patient was admitted to the intensive care unit (ICU) and received conservative treatment. On his seventh day in the hospital, follow-up magnetic reso- 


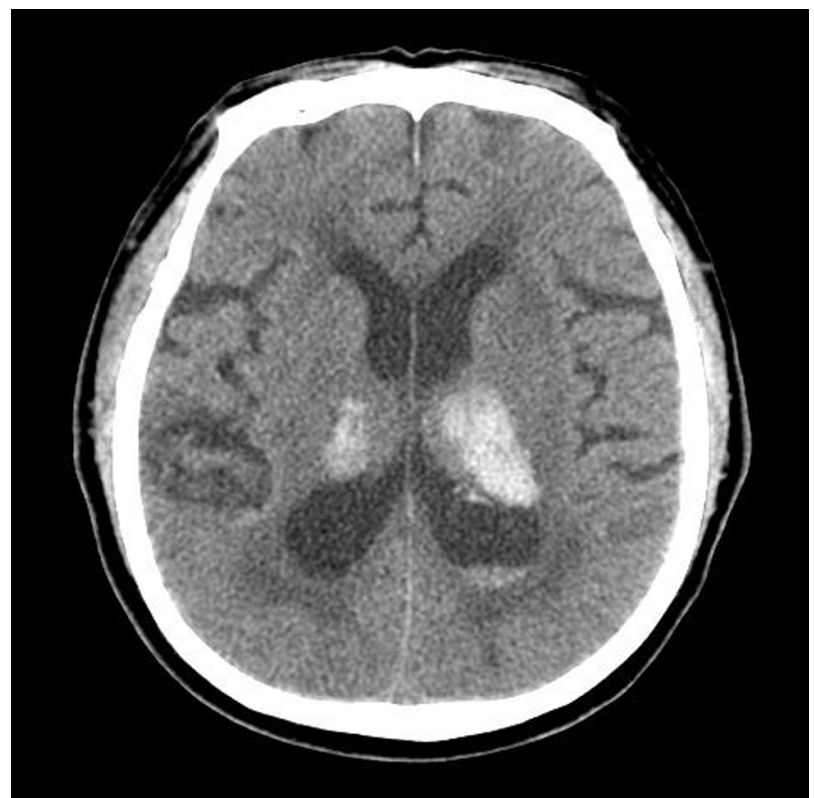

Fig. 1. A 73-year-old male patient (case 1) with spontaneous, simultaneous bithalamic hemorrhage. Brain computed tomography shows bilateral thalamic hemorrhage with intraventricular hemorrhage in the lateral ventricles.

nance imaging (MRI) was performed and showed confluent white matter signals in the periventricular region and in the centrum semiovale; we concluded that he probably had microangiopathic changes in addition to the bithalamic hemorrhage and the intraventricular hemorrhage (Fig. 2). Transfemoral cerebral angiography (TFCA) showed multiple vascular irregularities in the anterior cerebral arteries, middle cerebral ar-

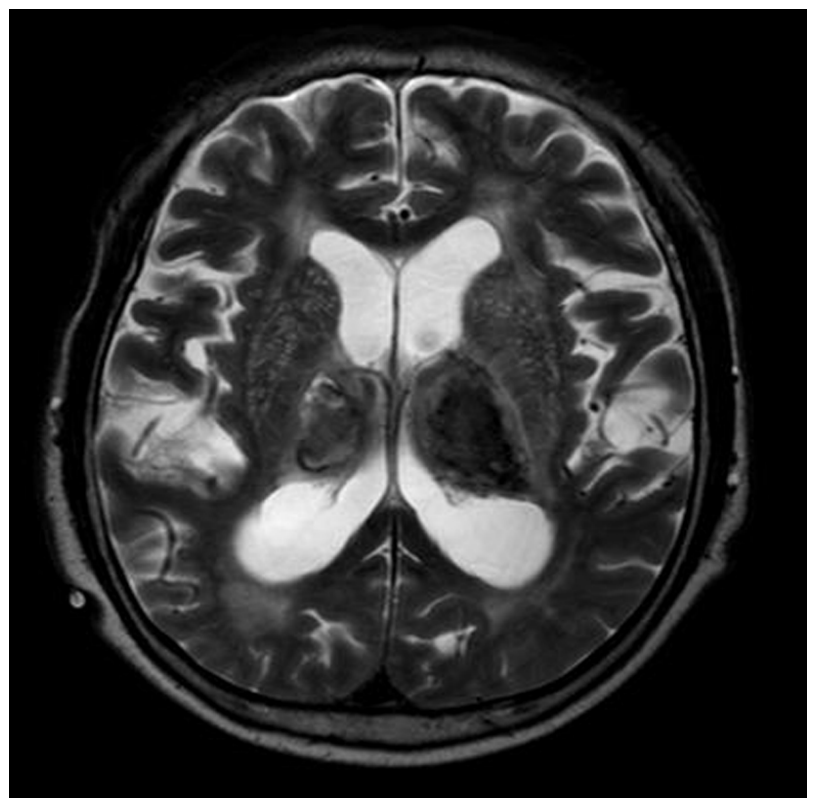

Fig. 2. T2-weighted brain magnetic resonance imaging of case 1. Microangiopathic changes in the periventricular area with early subacute bithalamic hemorrhage are noted.

teries, and vertebral arteries, as well as mild atheroma in the bilateral proximal internal carotid arteries (ICA) (Fig. 3). CT, which was repeated after five weeks, showed focal infarcts in the right corona radiata; however, no additional neurologic deficits were observed. Diffusion MRI showed recent focal infarcts in the right corona radiata and subacute stage infarcts in the right occipital lobe and the left temporo-occipital lobe. While
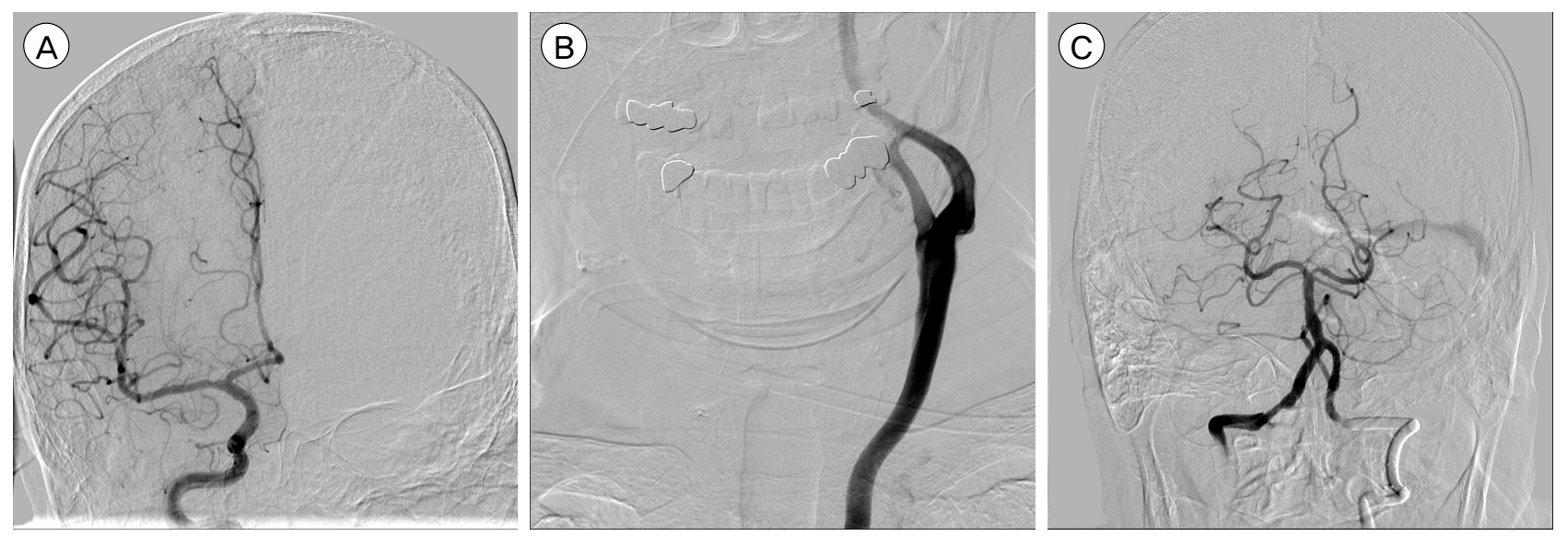

Fig. 3. Transfemoral carotid angiography (case 1) was performed at the hospital 24 days after admission. (A) Multiple focal vascular stenosis in the anterior cerebral artery and middle cerebral artery. (B) Mild atheroma is shown in the left cervical carotid bifurcation. (C) Focal stenosis is shown in the right vertebral artery. 
undergoing rehabilitation, the patient suffered from recurrent pneumonia. He died of pneumonia within one year of suffering the bithalamic hemorrhage.

\section{Case 2}

A 60-year-old-man with no hypertension, diabetes mellitus, or other relevant medical history was admit-
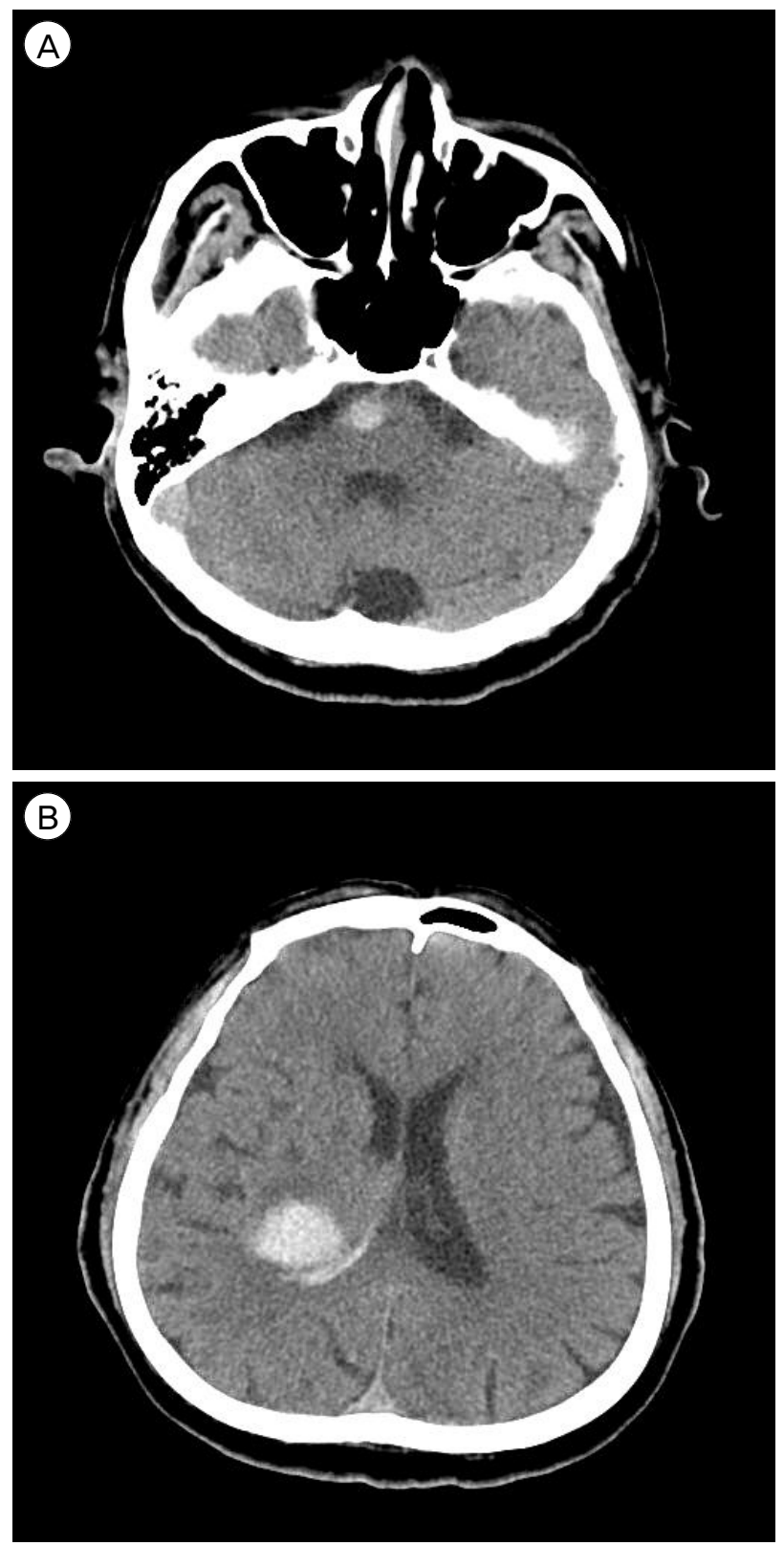

Fig. 4. A 60-year-old male patient (case 2) with spontaneous, simultaneous intracerebral hemorrhage. (A) Brain computed tomography shows intracerebral hemorrhage in the pons. (B) Acute right thalamus hemorrhage is noted. The two hemorrhages were completely separated spatially. ted to our hospital emergency room for weakness on the left side of his body. He was a social drinker and did not smoke. The patient's mental status was drowsy, and his Glasgow coma scale score was 14 (eye opening 4, verbal response 4, motor response 6). Isocoric pupil with $2 \mathrm{~mm} / 2 \mathrm{~mm}$ prompt light reflex
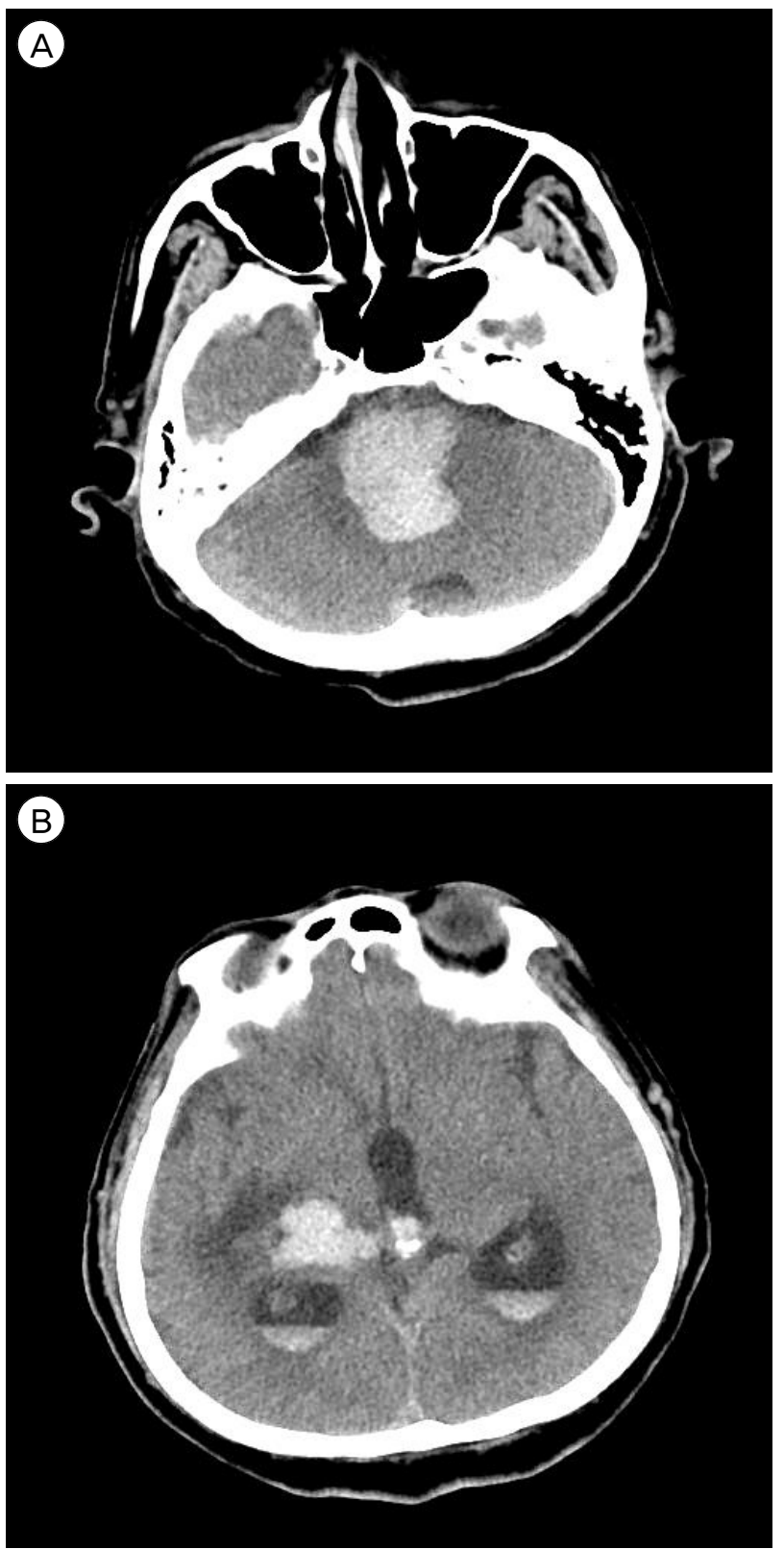

Fig. 5. Follow-up computed tomography of case 2 after neurologic deterioration into a coma. (A) An increased amount of intracerebral hemorrhage in the pons is compressing the fourth ventricle. (B) There is no significant change in the hemorrhage in the right thalamus. 
was noted, and his left side motor grade was II.

CT showed an acute ICH in the right thalamus and the right ventral pons (Fig. 4). According to the laboratory results, his $\mathrm{CBC}$ and coagulation battery were normal, however, he had hypokalemia, hyperlipidemia, and elevated levels of CRP, ESR, and D-dimer. He also had highly elevated liver enzymes, which had normalized at one-week follow up.

On the same day of his admission to the hospital, the patient showed sudden deterioration into a comatose state, and an increased amount of bleeding on the pons was identified (Fig. 5). His initial CT angiography showed diffuse calcified plaques in the bilateral distal ICA and focal stenosis in the right distal cavernous ICA and the right posterior cerebral artery P2 portion; however, there were no identifiable vascular malformations adjacent to the hematoma of the pons and thalamus (Fig. 6). He died two weeks after the onset of the hemorrhage.

\section{DISCUSSION}

\section{Incidence and location of multiple ICH}

ICH represents $8-14 \%$ of first-attack strokes, however, multiple, simultaneous $\mathrm{ICH}$ is an uncommon event. ${ }^{2)}$ Multiple ICH have been observed in only $2 \%$ of hemorrhagic strokes. ${ }^{15)}$ Yen et al. reported an incidence of $0.8 \%$ for simultaneous multiple ICH among all intracranial hemorrhages, Tanno et al. reported an incidence of $0.7 \%{ }^{19}{ }^{21)}$ In other studies, Mauriño et al. reported $2.8 \%$ out of 142 patients with hemorrhagic stroke and Stemer et al. reported 14 out of $412 \mathrm{ICH}$ patients $(3.4 \%){ }^{12) 17)}$

Spontaneous single ICHs occur predominantly in a deep location of the brain, the most common of which is the putamen, followed by the thalamus, the cer-
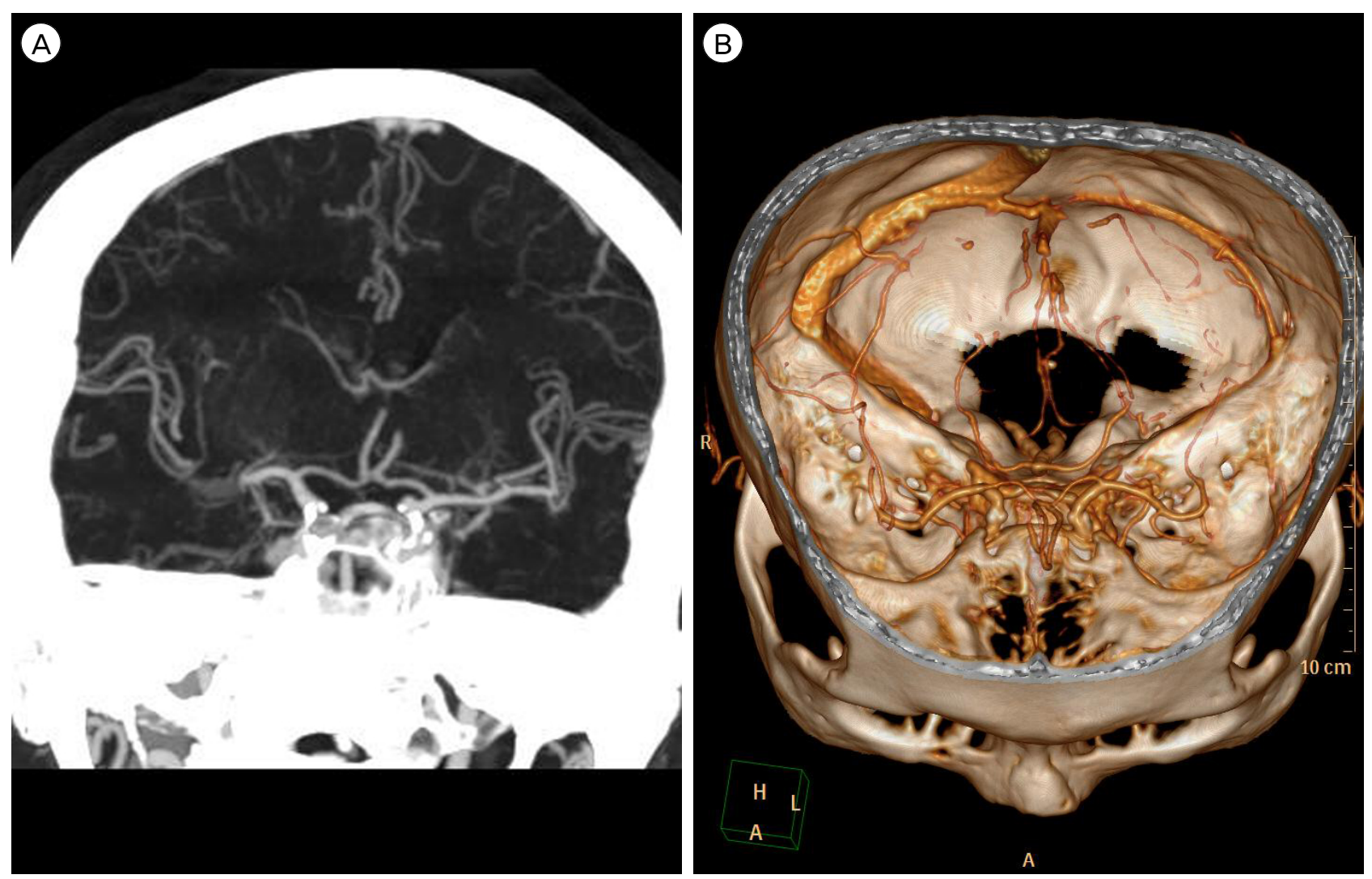

Fig. 6. Initial computed tomography angiography of case 2. (A) Diffuse calcified plaques in the bilateral distal internal carotid arteries are noted. (B) Focal stenosis in the right posterior cerebral artery, P2 portion, is shown. 
ebellum, and the subcortical white matter. However, in simultaneous multiple ICHs, it was most com- monly detected in the bilateral thalami and then the putamens (Tables 1 and 2). Infratentorial hemorrhage

Table 1. Review of previously reported cases of multiple spontaneous intracerebral hematomas

\begin{tabular}{|c|c|c|c|c|c|c|}
\hline Authors (Year) & Sex & Age & Symptoms & Locations & Undying disease & Outcome \\
\hline Choi JW, et al. $(2005)^{5)}$ & M & 70 & Unconscious (GCS 7) & Bil. Thalami & Hypertension & GOS 3 \\
\hline \multirow[t]{4}{*}{ Mauriño J, et al. $(2001)^{121}$} & $\mathrm{~F}$ & 59 & Headache, Rt. hemiparesis & Rt. Putamen, Lt. Thalamus & & mRS 4 \\
\hline & M & 58 & $\begin{array}{l}\text { Unconsciousness, } \\
\text { Lt. hemiparesis }\end{array}$ & Rt. Thalamus, Lt. Cerebellum & & mRS 5 \\
\hline & M & 63 & Headache. Rt. hemiparesis & Lt. Temporal lobe, Thalamus & & mRS 4 \\
\hline & $\mathrm{F}$ & 40 & Headache, Lt. hemiparesis & Bil. Putamen & & mRS 5 \\
\hline Sato $M$, et al. $(1986)^{14)}$ & M & 45 & Lt. hemiplegia & Bil. Putamen & None & Walk with a cane \\
\hline $2^{\text {nd }}$ citation from Sato (Miyasaka) ${ }^{141}$ & $\mathrm{~F}$ & 70 & Quadriparesis & Rt. Putamen, Lt. Thalamus & & Severe disable \\
\hline \multirow[t]{10}{*}{ Yen CP, et al. $(2005)^{211}$} & M & 55 & Seizure, Quadriparesis (GCS 3) & Bil. Putamen & Previous stroke & ADL 6 \\
\hline & M & 64 & Hemiparesis (GCS 6) & Bil. Putamen & & ADL 6 \\
\hline & M & 63 & Quadriparesis (GCS 11) & Bil. Thalami & Previous stroke & ADL 6 \\
\hline & M & 54 & Quadriparesis (GCS 3) & Lt. Putamen, Pons & Previous stroke & ADL 6 \\
\hline & $\mathrm{F}$ & 54 & Aphasia, Quadriparesis (GCS 6) & Rt. Thalamus, Lt. Putamen & & ADL 6 \\
\hline & $\mathrm{F}$ & 57 & $\begin{array}{l}\text { Hemiparesis, } \\
\text { hemianopsia (GCS 8) }\end{array}$ & Rt. Thalamus, Lt. Lobe & & ADL 3 \\
\hline & M & 69 & Quadriparesis (GCS 13) & Bil. Thalami & & ADL 5 \\
\hline & $\mathrm{F}$ & 68 & Quadriparesis (GCS 11) & Bil. Thalami & Previous stroke & ADL 4 \\
\hline & $\mathrm{F}$ & 73 & Hemiparesis, seizure (GCS 8) & Rt. Thalamus, lobe, Lt. Lobe & Previous stroke & ADL 4 \\
\hline & M & 49 & Quadriparesis (GCS 3) & Bil. Putamen & Previous stroke & ADL 8 \\
\hline Imai K $(2000)^{6)}$ & M & 54 & Unconsciousness, tetraparesis & Bil. Thalami & Hypertension & Severely disabled \\
\hline $2^{\text {nd }}$ citation from Imai (Azuma) ${ }^{6}$ & M & 51 & Dysarthria & Bil. Thalami & Hypertension & Severely disabled \\
\hline $2^{\text {nd }}$ citation from Imai (Nakasato) ${ }^{6)}$ & M & 51 & Dysarthria & Bil. Thalami & Hypertension & Good recovery \\
\hline $2^{\text {nd }}$ citation from Imai (Sunada) $)^{6}$ & $\mathrm{~F}$ & 60 & $\begin{array}{l}\text { Dysarthria, tetraparesis, } \\
\text { pseudobulbar palsy }\end{array}$ & Bil. Thalami & Hypertension & Severely disabled \\
\hline $2^{\text {nd }}$ citation from Imai (Ogawara) $)^{6}$ & M & 58 & $\begin{array}{l}\text { Gait disturbance, Hemiparesis, } \\
\text { memory disturbance }\end{array}$ & Bil. Thalami & Hypertension & Good recovery \\
\hline Sunada, et al. $(1999)^{18)}$ & M & 60 & Unconsciousness, tetraparesis & Bil. Thalami & None & Dead \\
\hline Amin $O$ et al. $(2010)^{11}$ & M & 45 & Lt. hemiparesis & Rt. Putamen, Rt. cerebellum & Hypertension & Walk with a cane \\
\hline \multirow[t]{2}{*}{ Kabuto $M$, et al. $(1995)^{7 /}$} & M & 65 & Tetraplegia, unconsciousness & Bil. Putamen & Hypertension & Dead \\
\hline & $\mathrm{F}$ & 80 & Tetraplegia, unconsciousness & Bil. Thalami & Hypertension & Vegetative state \\
\hline \multirow[t]{2}{*}{ Kohshi K, et al. $(2000)^{9 /}$} & $\mathrm{F}$ & 76 & Hemiplegia & Rt. Thalamus, Lt. Putamen & Hypertension, DM & Walk with a cane \\
\hline & $\mathrm{F}$ & 54 & Hemiplegia & Lt. Putamen, Thalamus & Hypertension & Walk with a cane \\
\hline \multirow[t]{8}{*}{ Sorimachi T, et al. $(2007)^{16)}$} & M & 45 & & Bil. Putamen & & \\
\hline & $\mathrm{F}$ & 73 & & Rt. Thalamus, Lt. Lobe & & \\
\hline & M & 72 & & Rt. Thalamus, Lt. Lobe & & \\
\hline & $\mathrm{F}$ & 89 & & Lt, Frontal, Lt. Temporal & & \\
\hline & M & 68 & & Rt, Frontal, Rt. Temporal & & \\
\hline & M & 44 & & Bil, Putamen & & \\
\hline & M & 68 & & Lt. Thalamus, Lt. Lobe & & \\
\hline & $\mathrm{F}$ & 83 & & Bil. Putamen & & \\
\hline \multirow[t]{2}{*}{ Present cases } & M & 73 & Unconsciousness, tetraparesis & Bil. Thalami & & Dead \\
\hline & M & 60 & Hemiplegia & Rt. Thalamus, pons & & Dead \\
\hline
\end{tabular}

mRS = Modified Rankin Scale; ADL = Kanaya's activity of daily life grading system; GCS = Glasgow coma scale; GOS = Glasgow outcome scale; Bil = bilateral; $\mathrm{DM}=$ diabetes mellitus 
was rare. Although the multiple ICHs were located in different hemispheres, they were usually related to the same circulation system. Thalamoperforating arteries are responsible for thalamic hemorrhage while putaminal hemorrhages originated from lenticulostriate arteries from the middle cerebral artery or proximal anterior cerebral artery in the anterior circulation.

\section{Causes and outcomes of multiple ICH}

Due to the small number of reported cases, the underlying pathology is still not known. Reported causative factors include hypertension, multiple microbleeding, cerebral amyloid angiopathy, vasculitis, administration of intravenous tissue plasminogen activator, asphyxiation, deep cerebral vein thrombosis, and neoplasm; these causative factors are similar to those for single spontaneous $\mathrm{ICH}^{4) 8) 11) 14) 16)}$ A summary of the previously reported cases of multiple $\mathrm{ICH}$ is shown in Table 1; review was limited to patients without secondary causes like blood dyscrasia and cases with subsequent bleeding, in which there is an

Table 2. Summary of the reported 37 patients with multiple spontaneous hemorrhages

\begin{tabular}{lc}
\hline \multicolumn{1}{c}{ Variables } & Number of patients \\
\hline Age (years) & 63.2 (44-89) \\
Sex (M:F) & $23: 14$ \\
Lateralization & \\
$\quad$ Bilateral & 24 \\
Same side & 4 \\
Locations* & \\
$\quad$ Thalamus & 36 \\
$\quad$ Putamen & 24 \\
$\quad$ Subcortical & 11 \\
Pons & 2 \\
Cerebellum & 1 \\
Glasgow outcome scale ${ }^{\dagger}$ & \\
1 & 10 \\
2 & 10 \\
3 & 4 \\
4 & 5 \\
5 & 0 \\
\hline * Locations are presented as number of lesions. \\
$\begin{array}{l}\text { Outcomes were originally presented as a different scale. Based } \\
\text { on the original articles the Glasgow outcome scales were arbitrarily } \\
\text { applied by the authors. }\end{array}$ \\
\end{tabular}

identifiable time interval between two discrete bleeding, were also excluded. As shown in this table, previous stroke, hypertension, and diabetes were the only underlying ICH related disease. There was no difference from the solitary ICH. Several studies have suggested hypertension as a major cause of simultaneous multiple $\mathrm{ICH}^{17}{ }^{17}$ Ooneda et al. suggested that patients with untreated hypertension are more likely to experience microaneurysms in the putamen or thalamus, and a rupture in any of these aneurysms could lead to development of simultaneous $\mathrm{ICH}^{13)}$ Neither case presented here had any of the specific causative factors; however, CT angiography showed vascular irregularities, multiple focal vessel stenosis, and calcified plaque. In our cases, no specific causative factors were found, therefore, we consider that these hemorrhages were spontaneous; however, in the second case, evaluation was insufficient to completely rule out underlying disease.

Yen et al., who compared patients with multiple ICHs to those with solitary ICH, found that hypertension was the only significant risk factor for development of multiple ICHs. They suggested that a longer duration of hypertension and subsequent prolonged and widespread degenerative changes of intraparenchymal arterioles might be involved in development of simultaneous multifocal bleedings. ${ }^{21)}$ Sorimachi et al., who performed T2*-weighted MR imaging (T2WMRI), found five or more microbleeds in multiple ICH patients. Higher number of microbleeds and high blood pressure were more frequent in multiple $\mathrm{ICH}$ patients than in single $\mathrm{ICH}$ patients and he recommended strict control of blood pressure in patients with multiple microbleeds on T2WMRI. ${ }^{16)}$ Due to the widespread nature of angiopathy, cerebral amyloid angiopathy related $\mathrm{ICH}$, which accounts for $5-20 \%$ of spontaneous ICH in elderly, often manifests as recurrent or simultaneous multiple $\mathrm{ICH}^{3}{ }^{3)}$

Clinical manifestations of multiple $\mathrm{ICH}$ are not standardized. The clinical signs and symptoms usually depend on the side and location of the 
hemorrhage. Patients present with various symptoms, such as decreased mental status, motor deficits, neuropsychological deficits, or dysarthria. Compared with single ICH patients, multiple ICH patients had lower Glasgow coma scale scores and higher rates of quadriparesis than hemiparesis. Different prognostic factors of multiple ICH have not been reported, however, patients have a poorer prognosis than single ICH patients. 5)12)21) Sato et al. suggested that multiple $\mathrm{ICH}$ patients experience severe neurological sequelae even if the sizes were smaller, because of markedly decreased cerebral blood flow in both cerebral hemispheres and disturbed both sides of the pyramidal tract and the sensory pathway at the same time. ${ }^{14)}$

\section{Probable patho-mechanisms of multiple sponta- neous ICH}

Thalamic bleeding originates from thalamic perforators of the posterior cerebral arteries, and pontine hemorrhage depends on the causative perforating artery, which can be found in the basilar paramedian perforators or short or long circumferential branches. Komiyama et al. found simultaneous hemorrhages from multiple lenticulostriate arteries in a man with hypertension and $\mathrm{ICH}^{10}{ }^{10}$ Simultaneous extravasation of contrast medium from both medial and lateral lenticulostriate arteries was observed during conventional angiography. If an ICH occurs, acute cerebrovascular changes subsequently occur. It could mean that hemodynamic change of the parent vessel can have a simultaneous effect on its perforators. Or, it is possible to assume that one area of bleeding and probable surge of regional pressure induce secondary bleeding in adjacent areas within a short period. ${ }^{21)}$ Vessel irregularities, such as strengthened jet flow, can occur in vulnerable penetrating arteries and could cause a subsequent ICH. Although in our cases, the simultaneous hemorrhages occurred in different regions, the causative vessels originated from the same circulation. Our angiography finding showed multiple vascular stenosis and microangiopathic changes, which can infer generally increased vascular fragility and increased risk of future hemorrhage.

For patients with long-standing hypertension and advanced cerebrovascular degeneration, initial hemorrhage can cause reflex increase in blood pressure and increased intracranial pressure, resulting in rupture of another vessel that is already weakened by chronic arterial hypertension. ${ }^{21)}$ The exact pathogenic mechanism is not clear, however, longstanding untreated hypertension is thought to be a major factor in multiple ICH and strict control of blood pressure is needed.

\section{CONCLUSION}

Hemorrhages are usually located in bilateral thalami and putamens and clinical symptoms depend on the location of the hemorrhage. The pathological mechanism and predisposing factors of simultaneous multiple ICH are still unknown. Hemodynamic change after solitary $\mathrm{ICH}$ or vessel irregularity by untreated hypertension, cerebral amyloid angiopathy, and microhemorrhage may cause simultaneous multiple ICH.

\section{REFERENCES}

1. Amin O, Rasheed AH, Ahmed SM. Simultaneous intracerebral haemorrhages; which came first, the supra-tentoral or the infra-tentorial one? BMJ Case Rep. 2010 Aug 19;2010.

2. Bamford J, Sandercock P, Dennis M, Burn J, Warlow C. A prospective study of acute cerebrovascular disease in the community: the Oxfordshire Community Stroke Project-1981-86. 2. Incidence, case fatality rates and overall outcome at one year of cerebral infarction, primary intracerebral and subarachnoid haemorrhage. J Neurol Neurosurg Psychiatry. 1990 Jan;53(1):16-22.

3. Biffi A, Greenberg SM. Cerebral amyloid angiopathy: a systematic review. J Clin Neurol. 2011 Mar;7(1):1-9.

4. Chanda A, Nanda A. Multiple cavernomas of brain presenting with simultaneous hemorrhage in two lesions: a case report. Surg Neurol. 2002 May;57(5):340-4; discussion 344-5.

5. Choi JW, Lee JK, Kim JH, Kim SH. Bilateral simultaneous hypertensive intracerebral hemorrhages in both thalami. J Korean Neurosurg Soc. 2005 Dec;38(6):468-70.

6. Imai K. Bilateral simultaneous thalamic hemorrhages-case Report. Neurol Med Chir (Tokyo). 2000 Jul;40(7):369-71.

7. Kabuto M, Kubota T, Kobayashi H, Nakagawa T, Arai 
Y, Kitai R. Simultaneous bilateral hypertensive intracerebral hemorrhages-two case reports. Neurol Med Chir (Tokyo). 1995 Aug;35(8):584-6.

8. Kase CS, Pessin MS, Zivin JA, del Zoppo GJ, Furlan AJ, Buckley JW, et al. Intracranial hemorrhage after coronary thrombolysis with tissue plasminogen activator. Am J Med. 1992 Apr;92(4):384-90.

9. Kohshi K, Abe H, Tsuru E. Simultaneous hypertensive intracerebral hematomas: two case reports. J Neurol Sci. 2000 Dec;181(1):137-9.

10. Komiyama M, Yasui T, Tamura K, Nagata Y, Fu Y, Yagura H. Simultaneous bleeding from multiple lenticulostriate arteries in hypertensive intracerebral haemorrhage. Neuroradiology. 1995 Feb;37(2):129-30.

11. Mühlau M, Schlegel J, Von Einsiedel HG, Conrad B, Sander D. Multiple progressive intracerebral hemorrhages due to an angiosarcoma: a case report. Eur J Neurol. 2003 Nov; 10(6):741-2.

12. Mauriño J, Saposnik G, Lepera S, Rey RC, Sica RE. Multiple simultaneous intracerebral hemorrhages: clinical features and outcome. Arch Neurol. 2001 Apr; 58(4):629-32.

13. Ooneda G, Yoshida Y, Suzuki K, Sekiguchi T. Morphogenesis of plasmatic arterionecrosis as the cause of hypertensive intracerebral hemorrhage. Virchows Archiv A Pathol Pathol Anat. 1973 Oct;361(1):31-8.

14. Sato M, Tanaka S, Kohama A, Sone T, Fukunaga M, Morita R. Spontaneous bilateral intracerebral hemorrhage occurring simultaneously-case report. Neurol Med Chir (Tokyo). 1986 Jul;26(7):545-7.
15. Seijo M, Ucles A, Gil-Nagel A, Balseiro J, Calandre L. [Multiple cerebral hematomas: review of 7 cases]. Rev Neurol. 1996 May;24(129):549-53. Spanish.

16. Sorimachi T, Ito Y, Morita K, Fujii Y. Microbleeds on gradient-echo $\mathrm{T} 2\left(^{*}\right)$-weighted $\mathrm{MR}$ images from patients with multiple simultaneous intracerebral haemorrhages. Acta Neurochir (Wien). 2007 Feb;149(2):171-6; discussion 176-7.

17. Stemer A, Ouyang B, Lee VH, Prabhakaran S. Prevalence and risk factors for multiple simultaneous intracerebral hemorrhages. Cerebrovas Dis. 2010 Aug;30(3):302-7.

18. Sunada I, Nakabayashi H, Matsusaka Y, Nishimura K, Yamamoto S. Simultaneous bilateral thalamic hemorrhage: case report. Radiat Med. 1999 Sep-Oct;17(5):359-61.

19. Tanno H, Ono J, Suda S, Karasudani H, Yamakami I, Isobe $\mathrm{K}$, et al. [Simultaneous, multiple hypertensive intracerebral hematomas: report of 5 cases and review of literature]. No shinkei Geka. 1989 Mar;17(3):223-8. Japanese.

20. van Asch CJ, Luitse MJ, Rinkel GJ, van der Tweel I, Algra A, Klijn CJ. Incidence, case fatality, and functional outcome of intracerebral haemorrhage over time, according to age, sex, and ethnic origin: a systematic review and meta-analysis. Lancet Neurol. 2010 Feb;9(2):167-76.

21. Yen $C P$, Lin $C L$, Kwan AL, Lieu AS, Hwang SL, Lin $\mathrm{CN}$, et al. Simultaneous multiple hypertensive intracerebral haemorrhages. Acta Neurochir (Wien). 2005 Apr;147(4):393-9; discussion 399. 